\title{
Morbidity and mortality in adults with congenital heart defects in the third and fourth life decade
}

\author{
Matthias J. Müller ${ }^{1}$ (C) Kambiz Norozi ${ }^{1,2}$. Jonas Caroline ${ }^{1} \cdot$ Nicole Sedlak $^{1} \cdot$ Jonas Bock $^{1} \cdot$ Thomas Paul $^{1}$. \\ Siegfried Geyer ${ }^{3}$. Claudia Dellas ${ }^{1}$
}

Received: 17 October 2021 / Accepted: 7 February 2022 / Published online: 1 March 2022

(c) The Author(s) 2022

\begin{abstract}
Objectives The population of adults with congenital heart defects (ACHD) is continuously growing. Data on morbidity and mortality of ACHD are limited. This longitudinal observational study examined a group of ACHD with surgically corrected or palliated congenital heart defects (CHD) during a 15-year period.

Methods ACHD that had participated in the initial study were invited for a follow-up examination. Mortality and hospitalization data were compared with a healthy control group.

Results From 05/2017 to 04/2019 a total of 249/364 (68\%) ACHD participated in the follow-up study: 21\% had mild, 60\% moderate and 19\% severe CHD. During the observational period, 290 health incidents occurred (cardiac catheterization 37\%, cardiovascular surgery $27 \%$, electrophysiological study/ablation $20 \%$, catheter interventional treatment $14 \%$, non-cardiac surgery 3\%). Events were more frequent in ACHD with moderate (53\%) and severe (87\%) compared to those with mild CHD $(p<0.001) .24$ individuals died at a median age of 43 years during the observation period. $29 \%$ of them had moderate and $71 \%$ severe CHD corresponding to a mortality rate of $0 \%, 0.29 \%$ and $1.68 \%$ per patient-year in ACHD with mild, moderate and severe CHD. Long-term survival was significantly reduced in patients with severe CHD in comparison to individuals with mild and moderate CHD $(p<0.001)$.

Conclusion After correction or palliation of CHD, there was remarkable ongoing morbidity and mortality in ACHD patients over the 15-year observation period, particularly in individuals with moderate and severe CHD when compared with the general population. Thus, life-long special care is required for all surgically corrected or palliated ACHD patients.
\end{abstract}

Siegfried Geyer and Claudia Dellas contributed equally.

Matthias J. Müller

matthias.mueller@med.uni-goettingen.de

1 Department of Pediatric Cardiology and Intensive Care Medicine, Georg August University, Robert-Koch-Str. 40, 37075 Goettingen, Germany

2 Pediatric Cardiology, Western University, London, ON, Canada

3 Medical Sociology Unit, Hannover Medical School, Hannover, Germany 


\section{Graphical abstract}

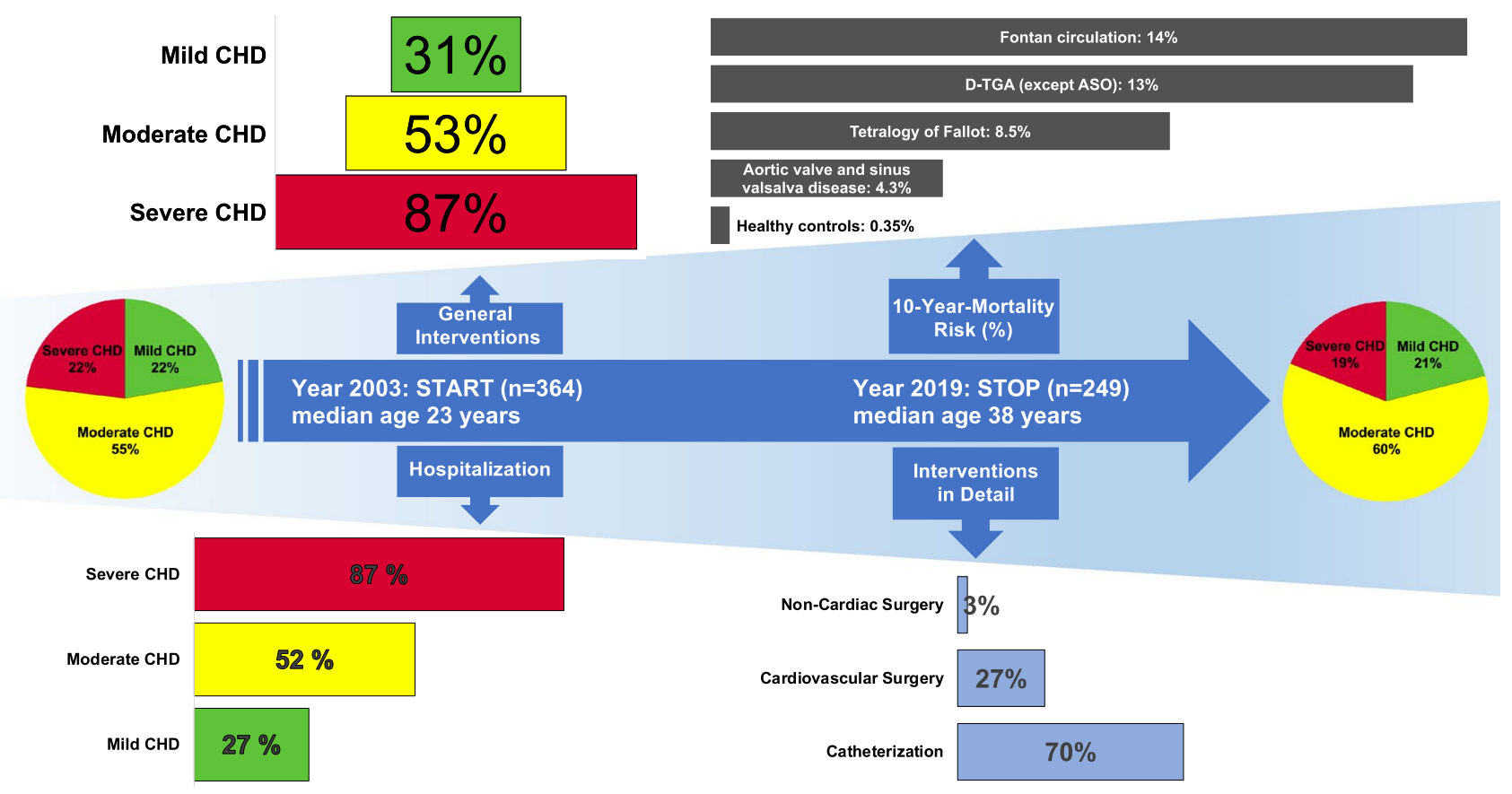

Keywords Adults with congenital heart defect $\cdot$ Morbidity $\cdot$ Mortality $\cdot$ Congenital heart defect $\cdot$ Observational study

$\begin{array}{ll}\text { Abbreviations } \\ \text { ACHD } & \text { Adults with congenital heart defect } \\ \text { AR } & \text { Aortic regurgitation } \\ \text { AS } & \begin{array}{l}\text { Aortic stenosis (valvulär/subvalvulär/ } \\ \text { supravalvulär) }\end{array} \\ \text { ASD } & \text { Atrial septal defect } \\ \text { CHD } & \text { Congenital heart defect } \\ \text { ccTGA } & \text { Congenitally corrected transposition of the great } \\ & \text { arteries } \\ \text { dTGA } & \text { Dextroposition transposition of the great arteries } \\ \text { DILV } & \text { Double inlet left ventricle } \\ \text { DORV } & \text { Double outlet right ventricle } \\ \text { EPS } & \text { Electrophysiological study } \\ \text { F } & \text { Female } \\ \text { Fig. } & \text { Figure } \\ \text { HR } & \text { Hazard ratio } \\ \text { IQR } & \text { Interquartile range } \\ \text { LC } & \text { Life chances } \\ \text { M } & \text { Male } \\ \text { n.s } & \text { Not significant } \\ \text { Py } & \text { Patient years } \\ \text { PA } & \text { Pulmonary atresia } \\ \text { SOEP } & \text { German Socio-Economic Panel } \\ \text { TOF } & \text { Tetralogy of Fallot } \\ \text { TA } & \text { Tricuspid atresia } \\ \text { VF } & \text { Ventricular fibrillation }\end{array}$

VSD Ventricular septal defect

VT Ventricular tachycardia

\section{Introduction}

About $1 \%$ of all live births suffer from a malformation of the heart or great vessels. Thanks to advances in diagnostics and treatment, more than $90 \%$ of children with the whole spectrum of congenital heart defects (CHD) are reaching adulthood now. Thus, the population of adults with congenital heart defects (ACHD) is continuously increasing and aging [1]. In general, ACHD represents a relatively new patient population with a broad variety of CHD from mild to severe [2]. Regardless of severity, almost all patients with CHD suffer from chronic heart disease, which requires regular follow-up care by CHDspecialized cardiologists. Particular attention must be paid to potential residuals of corrected or palliated CHD and additional comorbidities [3]. The present longitudinal observational study was designed to examine the longterm course of patients with surgically corrected or palliated heart defects over a period of 15 years in a tertiary ACHD facility by examining the morbidity and mortality in comparison with controls from the general population. 


\section{Patients and methods}

In a previous cross-sectional study in our center from 2003 to 2004 (reviewed and approved by the ethics committee of Hannover Medical School under no. 3710, date: 04-102004 and by the University Clinic of Goettingen under no. 10/2/01, date: 01-03-2001) entitled Life Chances 1 (LC1), a total of 364 patients with various types of corrected or palliated CHD had been extensively studied [4, 5]. These patients had a median age of 24 (range 14 to 45 ) years. For the current study, Life Chances 2 (LC2), all 364 patients from LC1 were contacted by phone, via mail, or via their general practitioners (Fig. 1). Between 05/2017 and 04/2019, all patients were invited to our outpatient clinic for follow-up examination that included medical history, physical examination, ECG, 2D- and 3D-echocardiogram, blood sampling, exercise stress testing, and socio-medical interview (reviewed and approved by the ethics committee of the University of Goettingen, no. 15/8/14). Complexity of CHD was defined as mild, moderate, and severe according to the 2020 ESC Guidelines for the management of adult congenital heart disease [1]. In patients with multiple cardiac lesions, the lesion of highest complexity was assigned.

To evaluate the findings on morbidity and mortality in the patient sample, control groups were drawn from the German Socio-Economic Panel (SOEP) as a national longitudinal German population survey. Controls for comparing morbidity were drawn from the survey 2004 by using age, gender, and parental education as matching variables. Parental education was used as a replacement for own education as many patients had not completed school education when the first

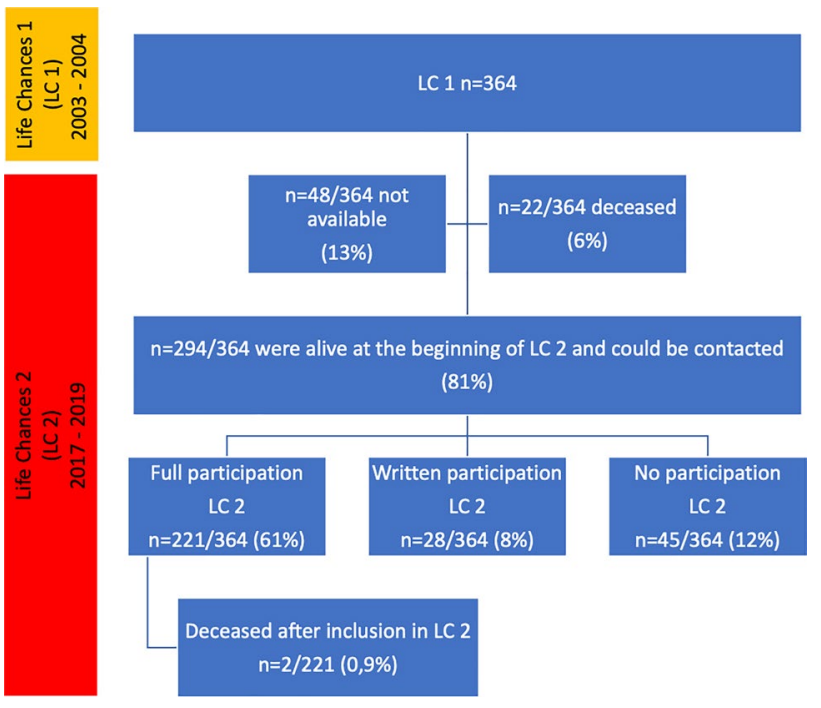

Fig. 1 Flowchart of patients who participated in LC2 (LC: Life Chances) survey was conducted. Finally, 363 cases with longitudinal records were drawn. For mortality, 1089 controls were available as also shorter observation periods could be allowed for.

\section{Patient and public involvement}

Patients were not involved in planning and realization of this project. During the initial cross-sectional study from 2003 to 2004, patients with various types of corrected or palliated CHD were consecutively recruited during visits from the outpatient clinic of the Department of Pediatric Cardiology and Intensive Care Medicine, Georg August University Medical Center, Goettingen, Germany. Between $05 / 2017$ and 04/2019, all patients were invited to the outpatient clinic for follow-up examinations. After the first and the second study, findings were presented and discussed in a symposium for patients.

\section{Statistics}

Statistical analyses were performed using SPSS ${ }^{\circledR} 26.0$ (IBM, New York, USA). Numerical data are presented as median and interquartile range (IQR). Differences between numerical data were calculated using non-parametric tests, Mann-Whitney- $U$ test, or Kruskal-Wallis test. Differences between variables were calculated by Chi-square test. Patient-years (py) were calculated as total years between inclusion into LC1 and LC2 or, if deceased, until date of death. For patients with an unknown date of death, $05 / 31 / 2017$ was inferred as the date of death which was the start of $L C 2$. Mortality was calculated by dividing the number of deaths by total patient-years between LC1 and LC2 . Long-term survival is displayed by Kaplan-Meier survival curves and was tested for significance by the log-rank test. Risk for death was calculated by Cox regression analysis and described as hazard ratio (HR). A $p$ value $<0.05$ was defined as error level.

\section{Results}

\section{Study population}

Of the 364 individuals of LC1, a total of 221 patients (61\%) followed the invitation for the follow-up examination for LC2 (Fig. 1). Another 28/364 (8\%) patients completed a socio-medical questionnaire only, resulting in a total attendance of 249/364 patients (68\%) at a median age of 38 (IQR: $33-47)$ years, while the youngest patient was 27 and the oldest was 60 years of age, respectively.

The remaining 115/364 (32\%) patients did not participate in LC2. The reasons included: 
1. The patient could not be reached/was lost to follow-up (48/364; 13\%).

2. $45 / 364(12 \%)$ patients refused to participate in LC2. Of those, $20 \%$ had a simple, $47 \%$ a moderate and 33\% a severe CHD, respectively. 14/45 (31\%) patients had been studied in LC1 and had not further regular cardiac checkups thereafter. The remaining 69\% (31/45) attended regular cardiac checkup at our tertiary ACHD facility, but could not be motivated to participate in LC2.

3. The patient had died $(22 / 364 ; 6 \%)$. Two others died shortly after inclusion in LC2, totaling 24 deaths. All patients who could be contacted but refused to participate in LC2 were assigned the status "alive" at the time of LC2 (Fig. 1).

\section{Follow-up visits from LC1 to LC2}

Two patient questionnaire surveys were conducted. Initially, patients were asked during data collection for $\mathrm{LC} 1$ and subsequently during data collection for LC2.

For clinical examination, there were no exactly defined periods of follow-up visits between LC1 and LC2. 63\% of LC2 study patients had presented to regular cardiology examinations, i.e., at least once every 5 years. The remaining $37 \%$ had not undergone regular cardiac follow-up assessment $(p<0.05)$. The severity of CHD had an impact on regular cardiologic follow-up visits: $35 \%$ with mild CHD had regular follow-up visits vs. $64 \%$ with moderate and $89 \%$ with severe CHD.

\section{Cardiac malformations}

For detailed analyses of LC1 and LC2, all cardiac malformations present in more than 14 individuals in LC1 were grouped as a specific entity. Rare cardiac defects involving less than 14 patients were classified as "others". All patients with univentricular hearts who had any type of a Fontan Circulation were assigned to "Fontan Circulation" irrespective of the specific underlying cardiac malformation. In this way, all patients could be assigned to ten different diagnosis groups (Fig. 2). Detailed basic information from all patients of LC1 and LC2 are displayed in Table 1.

\section{Severity of CHD}

Distribution of CHD severity among participants of LC1 and LC2 did not differ significantly. Severity of CHD of the 364 patients (female $n=154,42 \%$ ) of LC1 was as follows: mild in 81 patients (22\%), moderate in $199(55 \%)$ and severe in 84 (23\%). Of the 249 patients in LC2 (female $n=105,42 \%$ ), 52 patients $(21 \%)$ had mild, $150(60 \%)$ had moderate and 47 (19\%) had severe CHD (n.s.).

In contrast, distribution of CHD severity was significantly different in patients who were lost to follow-up

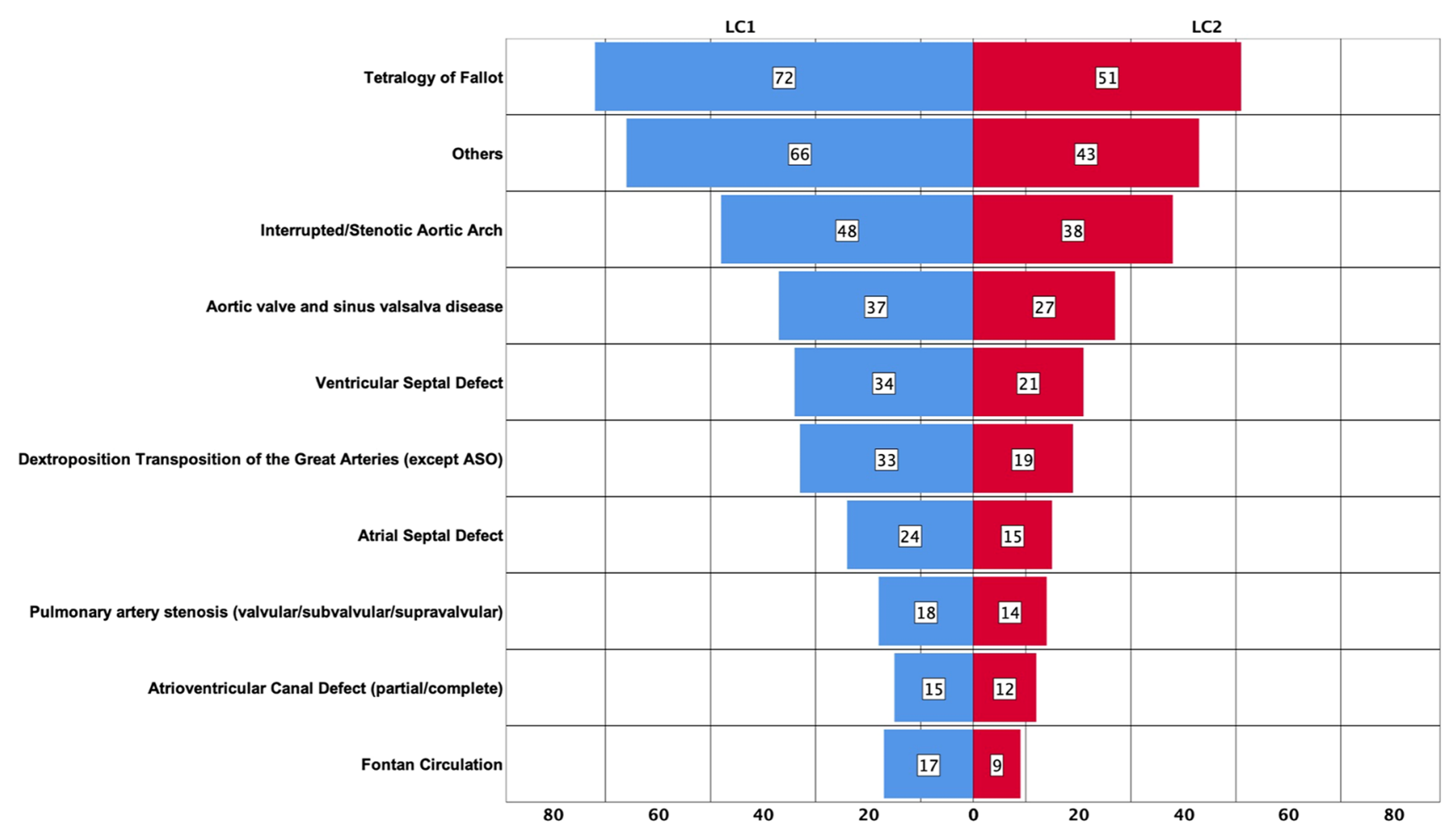

Fig. 2 Vertical bar charts show the number of patients per diagnosis group at LC1 (left bar chart) and, at LC2 (right bar chart) 
Table 1 Detailed patient characteristics according to the ten diagnosis groups at LC1 and LC2

\begin{tabular}{|c|c|c|c|c|c|c|}
\hline & Congenital heart defect $(n ; \%)$ & $\begin{array}{l}\text { Gender } \\
\text { Female }(n ; \%)\end{array}$ & $\begin{array}{l}\text { Age in years } \\
\text { (median; } \\
\text { range) }\end{array}$ & $p$ value & $\begin{array}{l}\text { Body mass } \\
\text { index (median; } \\
\text { range) }\end{array}$ & $p$ value \\
\hline & Aortic valve and sinus valsalva & & & & & \\
\hline LC I & $37 / 364 ; 10 \%$ & $8(22 \%)$ & $27.0 ; 14.0-43.0$ & & $23.7 ; 16.9-38.0$ & \\
\hline \multirow[t]{2}{*}{ LC II } & $27 / 249 ; 11 \%$ & $4(15 \%)$ & $41.0 ; 28.0-58.0$ & $\mathrm{p}<0.001$ & $25.2 ; 19.1-49.6$ & $p=0.01$ \\
\hline & $A S D$ & & & & & \\
\hline LC I & $24 / 364 ; 7 \%$ & $14(58 \%)$ & $19.5 ; 14.0-42.0$ & & $23.1 ; 16.0-37.6$ & \\
\hline \multirow[t]{2}{*}{ LC II } & $15 / 249 ; 6 \%$ & $9(60 \%)$ & $35.0 ; 27.0-56.0$ & $\mathrm{p}<0.001$ & $23.7 ; 19.0-33.5$ & $p<0.023$ \\
\hline & Atrioventricular canal defect & & & & & \\
\hline LC I & $15 / 364 ; 4 \%$ & $8(53 \%)$ & $23.0 ; 15.0-39.0$ & & $22.1 ; 17.4-34.2$ & \\
\hline \multirow[t]{2}{*}{ LC II } & $12 / 249 ; 5 \%$ & $7(58 \%)$ & $39.5 ; 29.0-52.0$ & $p<0.001$ & $24.1 ; 19.9-36.1$ & $p=0.003$ \\
\hline & $\begin{array}{l}\text { Dextroposition transposition of } \\
\text { atrial switch operation }\end{array}$ & & & & & \\
\hline LC I & $33 / 364 ; 9 \%$ & $7(21 \%)$ & $22.0 ; 16.0-42.0$ & & $22.2 ; 16.6-34.8$ & \\
\hline \multirow[t]{2}{*}{ LC II } & $19 / 249 ; 8 \%$ & $4(21 \%)$ & $35.0 ; 30.0-49.0$ & $p<0.001$ & $25.7 ; 18.1-33.6$ & $p=0.002$ \\
\hline & Fontan Circulation & & & & & \\
\hline LC I & $17 / 364 ; 5 \%$ & $9(53 \%)$ & $29.0 ; 14.0-39.0$ & & $22.1 ; 17.6-34.2$ & \\
\hline \multirow[t]{2}{*}{ LC II } & $9 / 249 ; 4 \%$ & $5(56 \%)$ & $37.0 ; 29.0-52.0$ & $p<0.001$ & $22.4 ; 20.8-33.3$ & $p=0.008$ \\
\hline & Interrupted/stenotic aortic arch & & & & & \\
\hline LC I & $48 / 364 ; 13 \%$ & $18(38 \%)$ & $23.0 ; 14.0-42.0$ & & $23.7 ; 16.3-32.4$ & \\
\hline \multirow[t]{2}{*}{ LC II } & $38 / 249 ; 15 \%$ & $16(42 \%)$ & $38.0 ; 28.0-56.0$ & $p<0.001$ & $25.6 ; 17.0-33.7$ & $p=<0.001$ \\
\hline & $\begin{array}{l}\text { Pulomonary artery stenosis (ve } \\
\text { alvular) }\end{array}$ & & & & & \\
\hline LC I & $18 / 364 ; 5 \%$ & $8(44 \%)$ & $23.5 ; 14.0-44.0$ & & $23.6 ; 17.5-33.5$ & \\
\hline \multirow[t]{2}{*}{ LC II } & $14 / 249 ; 6 \%$ & $6(43 \%)$ & $37.028 .0-58.0$ & $p<0.001$ & $26.3 ; 17.0-45.4$ & $p=0.027$ \\
\hline & Tetralogy of Fallot & & & & & \\
\hline LC I & $72 / 364 ; 20 \%$ & $34(47 \%)$ & $32.0 ; 15.0-44.0$ & & $23.6 ; 16.9-31.5$ & \\
\hline \multirow[t]{2}{*}{ LC II } & $51 / 249 ; 20 \%$ & $22(43 \%)$ & $47.0 ; 29.0-59.0$ & $p<0.001$ & $24.9 ; 20.7-41.0$ & $p=<0.001$ \\
\hline & Ventricular septal defect & & & & & \\
\hline LC 1 & $34 / 364 ; 9 \%$ & $13(38 \%)$ & $21.0 ; 14.0-45.0$ & & $23.5 ; 18.9-34.7$ & \\
\hline \multirow[t]{2}{*}{ LC II } & $21 / 249 ; 8 \%$ & $9(43 \%)$ & $36.0 ; 28.0-60.0$ & $p<0.001$ & $25.7 ; 19.0-45.0$ & $p=0.016$ \\
\hline & Others & & & & & \\
\hline LC I & $66 / 364 ; 18 \%$ & $35(53 \%)$ & $23.5 ; 14.0-44.0$ & & $22.7 ; 16.3-35.3$ & \\
\hline LC II & $43 / 249 ; 17 \%$ & $23(54 \%)$ & $35.0 ; 27.0-58.0$ & $p<0.001$ & $25.116 .0-39.7$ & $p=0.002$ \\
\hline
\end{tabular}

$(n=48)$ compared to patients of LC2. Patients who were lost to follow-up had significantly more often mild than moderate and severe CHD, respectively $(p=0.001)$. In general, the inclusion rate between $\mathrm{LC} 1$ and $\mathrm{LC} 2$ decreased for each CHD group by approximately $20-30 \%$. It is of note, that the highest non-responder rates were present in the groups of patients with dextroposition transposition of the great arteries (dTGA, 14/33; 42\%) and Fontan Circulation $(8 / 17 ; 47 \%) .5 / 14(36 \%)$ patients with dTGA had died between LC1 and LC2, 3/14 (21\%) could not be reached and 6/14 (43\%) did not want to participate in LC2. Reasons for non-participation in LC2 for patients with a Fontan circulation were death in $3 / 8(38 \%)$, lost to followup in $1 / 8(13 \%)$ or refusal to participate in $4 / 8(50 \%)$.

\section{Hospitalizations}

Hospitalization records were available from 234 individuals who participated in LC2. Of those, 147 (63\%) needed hospitalization during follow-up. 127/147 (86\%) ACHD patients were admitted to the hospital for cardiac reasons. Annual hospitalization rates increased with severity of CHD (Fig. 3). Compared to 238 healthy controls matched for age, sex and education, hospitalization rates were significantly higher for patients with CHD than for controls $(p=0.008)$. However, this finding was mainly related to patients with severe CHD (Fig. 3). 
Fig. 3 Hospitalizations per year $($ mean $\pm \mathrm{SD})$ of patients with mild, moderate and severe CHD and healthy individuals

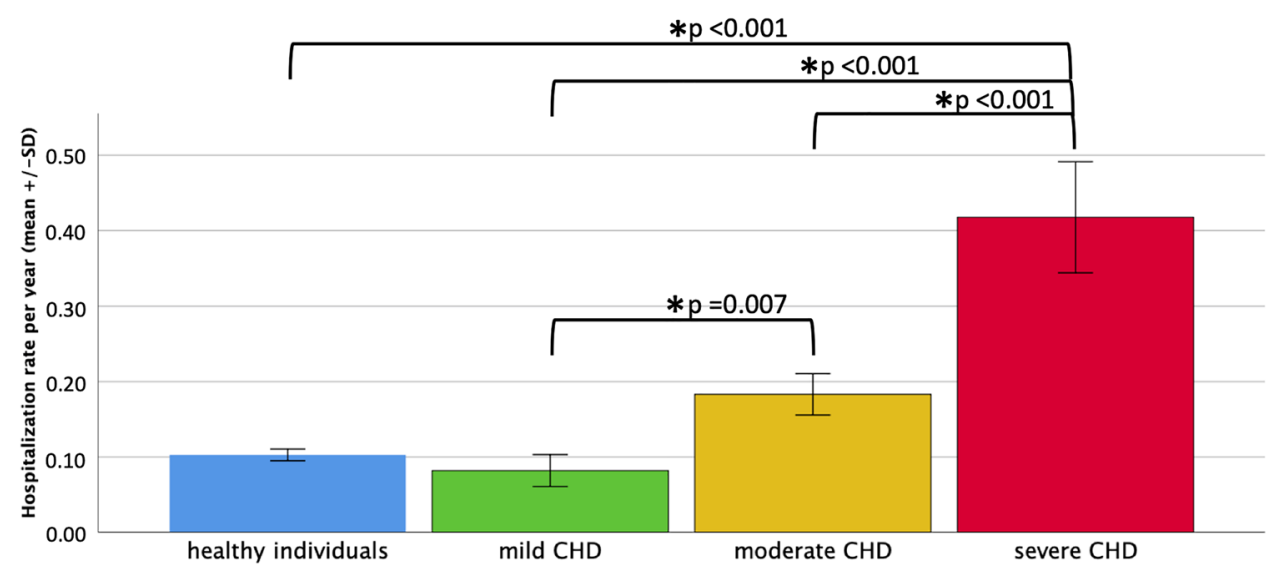

\section{Morbidity}

A total of 290 interventions were performed between $\mathrm{LCl}$ and $L C 2$ including cardiac catheterization $(n=106 / 290$; $37 \%)$, cardiovascular surgery $(n=79 / 290 ; 27 \%)$, electrophysiological study (EPS) and/or catheter ablation $(n=57 / 290 ; 20 \%)$, interventional catheterization $(n=39 / 290 ; 13 \%)$ and non-cardiac surgery $(n=9 / 290$; $3 \%)$. Interventions were more frequent in patients with moderate CHD (78/146 patients, 53\%) and severe CHD (41/47 patients, $87 \%)$ than in individuals with mild CHD $(15 / 48$ patients, $31 \% ; p<0.001)$. Importantly, this effect was not influenced by age, as there was no age difference between individuals with mild (median age 36.0; IQR 33.0-43.3 years), moderate (median age 40.0; IQR 33.8-48.0) and severe CHD (median age 35.0; IQR 33.0-43.0 years; $p=$ n.s. for each group tested against each other).

\section{Mortality}

For assessment of mortality, all patients who were not available at LC2 $(n=48)$ were excluded from further analysis. Thus, survival status at LC2 was known from 316/364 (87\%) patients. During the follow-up period between LC1 and LC2 covering a total of 4.285 patient-years, $24 / 316$ patients had died (8\%) yielding a total mortality rate of $0.56 \% /$ patient-year. In patients with severe CHD, longtime survival was significantly impaired when compared to patients with mild and moderate CHD $(p<0.001$; Fig. 4). Patients had died at a median age of 43 (IQR: $38-49)$ years. Causes of death were known in 14/24 (58\%) patients, of which $71 \%$ were related to CHD (Table 2). None of the deceased patients had mild CHD, while 7 (29\%) had moderate and 17 patients (71\%) had severe CHD. Women and men were equally distributed among the deceased individuals. Figures revealed a mortality
Fig. 4 Survival from LC1 to LC2

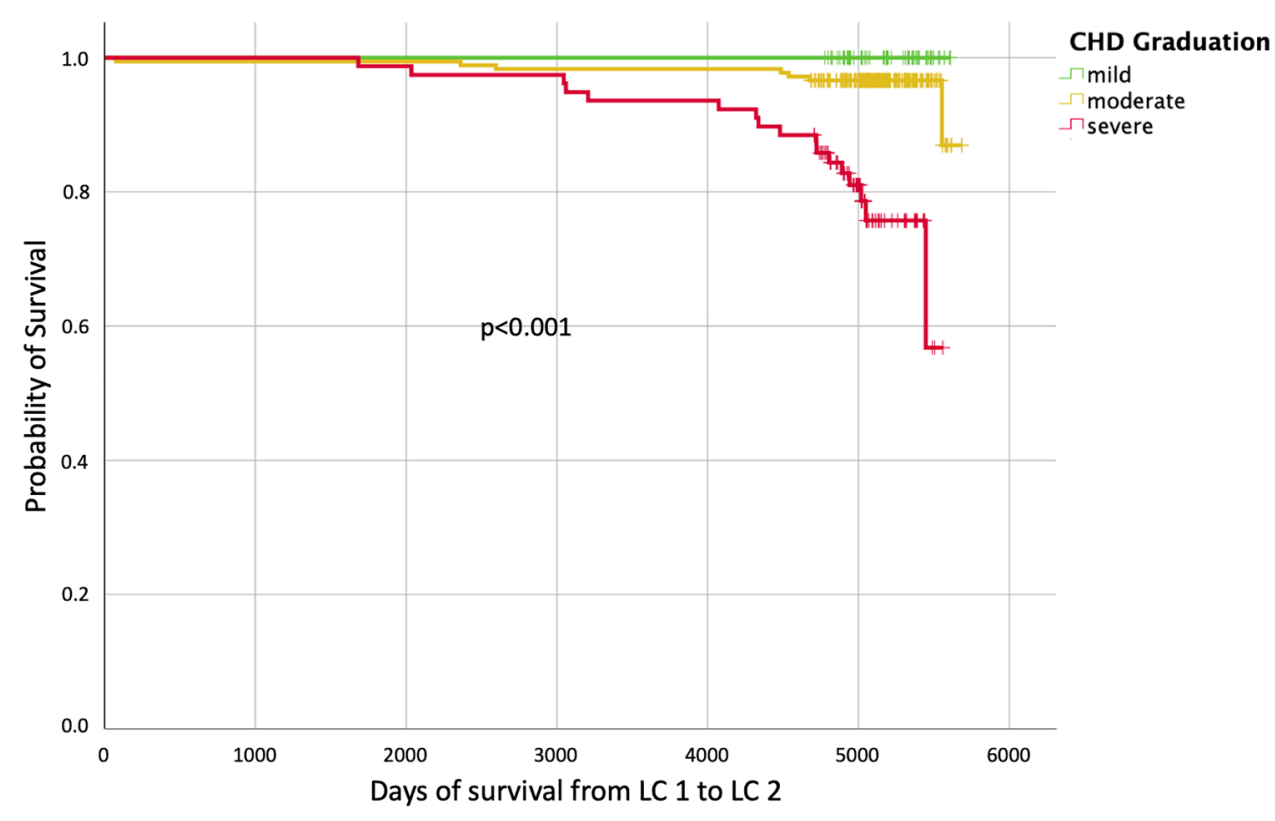


Table 2 Details of the congenital heart defect, the cause of death (if known) and the patient's age at the time of death

\begin{tabular}{|c|c|c|c|c|}
\hline No & CHD & Sex & Causes of death & Age at death (year) \\
\hline 1 & AS & M & Unknown & 36 \\
\hline 2 & AS & M & Unknown & 45 \\
\hline 3 & ccTGA & M & $<90$ days after heart transplantation with complicated course & 46 \\
\hline 4 & ccTGA & M & Unknown & Unknown \\
\hline 5 & DILV, Fontan & $\mathrm{F}$ & Failing Fontan & 28 \\
\hline 6 & DORV & $\mathrm{F}$ & Unknown & Unknown \\
\hline 7 & DORV & M & Unknown & Unknown \\
\hline 8 & dTGA, Mustard & M & Liver carcinoma & 51 \\
\hline 9 & dTGA, Mustard & M & Unknown & Unknown \\
\hline 10 & dTGA, Mustard & $\mathrm{F}$ & Unknown & 28 \\
\hline 11 & dTGA, Mustard & M & Unknown & Unknown \\
\hline 12 & dTGA, Rastelli & M & Decompensated heart failure & 47 \\
\hline 13 & $\mathrm{HCM}$ & M & Decompensated heart failure & 39 \\
\hline 14 & M. Ebstein, Fontan & $\mathrm{F}$ & $\begin{array}{l}\text { Pulmonary aspergillosis due to immunosuppression after heart trans- } \\
\text { plantation } 14 \text { months ago }\end{array}$ & 48 \\
\hline 15 & Morbus Ebstein & $\mathrm{F}$ & Decompensated heart failure with multiorgan failure & 40 \\
\hline 16 & PA, Fontan & M & VT/VF & 39 \\
\hline 17 & PA, Fontan & $\mathrm{F}$ & Renal failure & 42 \\
\hline 18 & PA, Fontan & $\mathrm{F}$ & unknown & unknown \\
\hline 19 & PA, Fontan & M & unknown & 39 \\
\hline 20 & TA, Fontan & M & Failing Fontan and heart transplantation 2 days ago & 44 \\
\hline 21 & TA, Hemifontan & $\mathrm{F}$ & $<90$ days after heart transplantation with complicated course & 54 \\
\hline 22 & TOF & $\mathrm{F}$ & Endocarditis & 53 \\
\hline 23 & TOF & $\mathrm{f}$ & Metastatic colon carcinoma & 50 \\
\hline 24 & TOF & $\mathrm{f}$ & Aspiration & 31 \\
\hline
\end{tabular}

rate of $0 \%$ in the mild, $0.29 \%$ in the moderate, and $1.68 \%$ in the severe CHD group per patient-year, respectively. When compared to patients with mild and moderate CHD, patients with severe CHD had a nearly eightfold higher risk of death (HR 7.97, IQR 1.12-56.62, $p=0.038$ ) than patients with mild CHD and a sixfold higher risk of decease (HR 6.25, IQR 2.58 to 15.13, $p<0.001$ ) than individuals with moderate CHD, respectively. The highest mortality rate occured in patients with Fontan Circulation $(19 \%, 1.4 \%$ /patient-year) followed by patients with dTGA after atrial switch operation $(16 \%, 1.3 \%$ /patientyear; see Table 3). When compared to healthy controls matched for age, sex, and education, patients with CHD had a 16-fold increase in mortality during the study period. During the same time, $5 / 1089(0.46 \%)$ healthy individuals had died reflecting a mortality of $0.035 \%$ per personyear $(p<0.0001)$. In healthy controls, mortality ranged between 0 and $1 \%$ per 5 -year-age group for all ages including those individuals who had already been in the "higher" age groups above 31 years at LC1 (Fig. 5). In contrast, patients with CHD had a significantly increased mortality compared to their age-matched healty controls for all age groups ( $p<0.05$ per age group). This finding emerged
Table 3 Annual mortality risk (\%) according to the diagnosis groups

\begin{tabular}{ll}
\hline Patient group with cases of death & $\begin{array}{l}\text { Mortality risk per } \\
\text { patient-year }(\%)\end{array}$ \\
\hline Aortic valve and sinus Valsalva disease & 0.43 \\
Tetralogy of Fallot & 0.85 \\
Others & 0.87 \\
Dextroposition transposition of the great arteries & 1.3 \\
$\quad$ except atrial switch operation & \\
Fontan circulation & 1.4 \\
Total & 0.56 \\
Healthy individuals & 0.035 \\
\hline
\end{tabular}

irrespective of younger or older age at the beginning of the study, revealing the greatest difference for those individuals above 31 years (Fig. 5).

\section{Socio-medical interview}

Data on the socio-medical interview were collected and analyzed by the Medical Sociology Unit, Hannover Medical School. A focus was placed on "Life chances after surgery 
Fig. 5 Death in controls (blue line) to study population with CHD (red line). Age at LC1 was used as the baseline for statistical analysis. There was a significant difference in death between controls and CHD patients in each age group $(p \leq 0.012)$

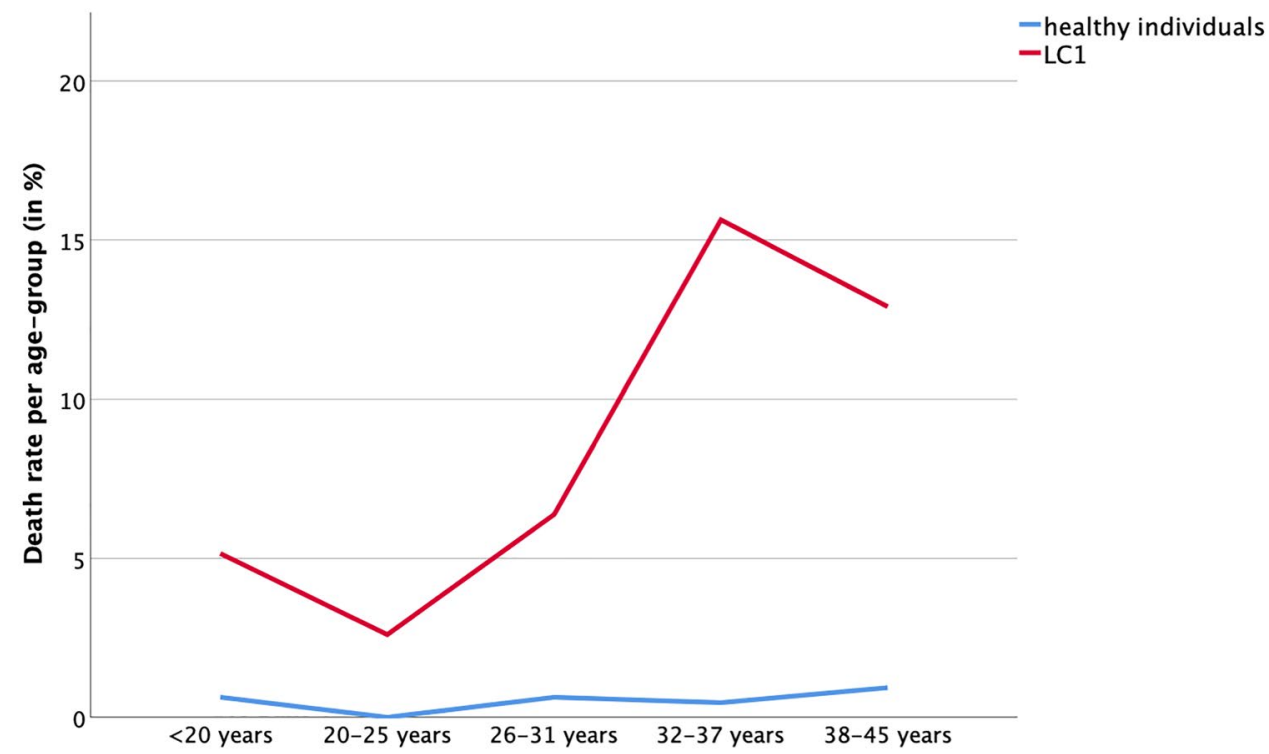

of congenital heart disease". The educational and occupational performance of patients over the 15 years period was examined. Patient data were compared with a control group generated from the German Socio-Economic Panel (SOEP), which included subjects from the first survey (2003-2004) and who were already included in LC2. Our patients, when compared with the control group, did not exibit any differences in intergenerational educational mobility. When compared for the intragenerational social mobility, however, there were more frequent downward changes [6].

\section{Discussion}

This longitudinal observational study provides long-term data of an ACHD population-in the middle of their life from a single tertiary ACHD center revealing high morbidity and mortality compared to age-matched healthy controls. Of particular importance is the fact, that patients studied were not limited to a singular entitiy of CHD, but represented the entire spectrum from mild to severe CHD.

Due to advances in diagnostics, interventions, surgery, and care for ACHD in the last decades, the number of ACHD reaching adulthood has steadily increased [7]. In childhood survivors of CHD, the mortality rate has declined by a comparable amount to the general public [8]. These fortunate findings are particularly applicable in patients with mild CHD who have shown comparable [9] or only slightly elevated mortality rates $[10,11]$ when compared to the general population as found in our study. None of the patients with mild CHD had died during the study period, while we were able to focus on a significantly longer follow-up period than previous studied [2]. It is of note, however, that we included fewer patients with mild CHD (21\%) compared to previous reports and to what is expected in the overall ACHD population (55\%) [7]. Our data reflect the pattern of care of ACHD patients in a large tertiary ACHD facility covering more patients with moderate and severe cardiac malformations. As reported before $[9,12]$, our patients with moderate and particularly severe CHD exhibited an increased mortality during the follow-up period. This finding is significant as our patients had already been "long-term survivors", i.e., survivors of childhood, when they had entered into LC1. Taking the potential study population at LC1 as a point of departure [13], 5\% had died, and another $16 \%$ did not respond. Considering all patients of this study, mortality correlated strongly with severity of underlying CHD. Altogether, ACHD patients of the present study had a 16-fold higher mortality rate than expected for age-matched healthy controls. Moreover, patients with severe CHD had a significantly increased risk of death than patients with mild and moderate CHD.

Currently, long-term survival for patients with univentricular circulation palliated by the contemporary modifications of the Fontan procedure improved to a predicted 30 -year survival of approximately $85 \%$ and without a sudden decline in survival or increase in mortality so far [14]. Almost 90\% (15/17) of our patients with a Fontan Circulation had been palliated before 1995, while the earliest procedure had been performed in December 1970. These patients had a median age of 29 years at LC1 and developed a remarkably high mortality rate of $14 \%$ per 10 years. Almost equally, a high mortality rate was also obserevd in patients with dTGA after atrial switch procedures. It is known that childhood survivors after atrial switch operation have a relatively stable period in their second and third decade of life with accelerated morbidity and mortality rate thereafter [15]. For example, in 91 consecutive patients who had a Mustard 
repair before 1980, Cuypers et al. calculated a cumulative survival of $84 \%$ after 10 years, $80 \%$ after 20 years, $77 \%$ after 30 years, and $68 \%$ after 39 years, respectively [16]. Data reflect a mortality rate of $0.3 \%$ per year for patients in their 20s and $1 \%$ per year in their 30s. At the start of LC1, nearly $90 \%$ of our dTGA patients were $<30$ years of age and only one had been operated after 1988. Yet, in their 20s, these patients had a high mortality rate $(13 \%)$ during the following decade. Slightly lower than patients with Fontan Circulation or dTGA after atrial switch procedure, the mortality rate of TOF patients was $8.5 \%$ for 10 years. This was comparable to TOF patients as reported by Cuypers et al. during their third and fourth decade of life [17]. Altogether, $71 \%$ of our deceased ACHD patients had a cardiovascular cause of death.

As expected, hospitalization rates were significant in our ACHD patients. During the study period, $63 \%$ of individuals had been hospitalized while $86 \%$ of those hospitalizations were related to cardiocasvular reasons. Hospitalization rates per year were significantly increased in patients with CHD compared to age-matched healthy controls and were particularly high in those with severe CHD. Similarly, a 10-year observation period from 2003 to 2012, as assessed by the United States Nationwide Inpatient Sample Database, found a considerable increase (up to 81.5\%) in hospitalizations of ACHD patients [18], independent of the reasons for hospitalization-treating or preventing complications and sequelae of the CHD and of comorbidities. These numbers reflect the increasing demands for medical care of an aging ACHD population, yet significantly earlier than expected from biological age [9]. Somewhat exaggeratedly expressed, it may be speculated that CHD patients exhibit progeria. For example, mortality of our middle-aged patients with severe CHD corresponded to the estimated 10-year risk for fatal cardiovascular events of the general population in men $\geq 60$ years of age or in women $\geq 70$ years of age exhibiting several risk factors like high blood pressure, hypercholesterinemia and smoking according to the ESC SCORE [19]. Whereas recent nationwide campaigns have focused on prevention of cardiovascular risk factors to avoid early development and late complications of cardiovascular diseases in the general population, knowledge of primary care physicians in Germany on care of ACHD patients is low [3] and ACHD patients do not often seek regular advice from ACHD specialists [20, 21]. Circumstances of pre-aging, elevated morbidity and mortality caused by cardiovascular and non-cardiovascular reasons emphasize the need for close and specialized surveillance of long-term ACHD survivors. This will improve outcome and shift survival closer to the general age-matched population, especially in patients with moderate and severe CHD.

In summary, our study showed significantly increased mortality in middle-aged ACHD patients with moderate and severe CHD over a follow-up period of 15 years. Morbidity was also impressively high, as there was a high demand for in-hospital cardiovascular interventions, particularly in patients with severe CHD. Moving forward, prevention of these events and timely intervention by ACHD specialists is of paramount importance in the care of ACHD patients.

\section{Summary and conclusions}

It is a substantial finding that this longitudinal observation study over 15 years on a well-defined cohort of ACHD confirms the findings of other studies with retrospective analysis of multicenter registry data or single-center data on high morbidity and mortality. It was not clear at that time, when the study started in 2003, to what extent ACHD patients are compromised concerning their health and life perspective. We believe, that our data derived 15 years later are a valuable endorsement of the concept [1] that CHD is a life-long chronic condition requiring long-term specialized care.

\section{Limitations}

The LC1 study was conducted at the Goettingen Heart Center to assess ACHD patients in an early era of the growing ACHD population, as at this time there was a lack of extensive data published on this topic. It was the aim of the LC2 study to figure out how this particular and welldescribed study population fared during the 15 subsequent years between LC1 and LC2. This longitudinal observational design over 15 years is in contrast to retrospective analyses of larger registries. This is the strength of the present study.

Loss of follow-up was remarkably low (13\%), but may have influenced our results, as the fate of these individuals is unclear. However, more patients with mild CHD were lost to follow-up than patients with severe CHD. Many factors may have played into this, from the perceived lack of need for follow-up visits by mild CHD patients, or more often changes in their place of residence as more individuals with mild CHD could not be reached after a period of 15 years. Furthermore, $12 \%$ of patients declined to participate in LC2 (45/364). The reasons were not precisely queried during data collection. Neither regular cardiology examinations at our tertiary ACHD facility nor higher severity of the CHD was a guarantee for participation in LC2. It may be speculated that these patients lacked an interest in participating in our repeat study or that they objected to take a closer look at their heart disease. Data presented was influenced by the fact that, when compared to previous studies, fewer patients with mild CHD were included in LC1 and LC2, reflecting the care of ACHD patients with moderate and severe CHD in a large tertiary ACHD center. Taking the limitations of this study 
into account, it will definitely be useful to conduct studies on ACHD patients in the future as multicenter studies on longitudinal observational basis.

\section{Appendix}

See below Tables 4 and 5.

Table 4 STROBE Statement-checklist of items that should be included in reports of observational studies

\begin{tabular}{|c|c|c|c|}
\hline & Item No & Recommendation & Page no \\
\hline \multirow[t]{2}{*}{ Title and abstract } & \multirow[t]{2}{*}{1} & (a) Indicate the study's design with a commonly used term in the title or the abstract & $1,3,7$ \\
\hline & & $\begin{array}{l}\text { (b) Provide in the abstract an informative and balanced summary of what was done and what } \\
\text { was found }\end{array}$ & 3 \\
\hline \multicolumn{4}{|l|}{ Introduction } \\
\hline Background/rationale & 2 & Explain the scientific background and rationale for the investigation being reported & 6 \\
\hline Objectives & 3 & State specific objectives, including any prespecified hypotheses & 6 \\
\hline \multicolumn{4}{|l|}{ Methods } \\
\hline Study design & 4 & Present key elements of study design early in the paper & 6 \\
\hline Setting & 5 & $\begin{array}{l}\text { Describe the setting, locations, and relevant dates, including periods of recruitment, exposure, } \\
\text { follow-up, and data collection }\end{array}$ & 6,7 \\
\hline \multirow[t]{2}{*}{ Participants } & \multirow[t]{2}{*}{6} & $\begin{array}{l}\text { (a) Cohort study_-give the eligibility criteria, and the sources and methods of selection of } \\
\text { participants. Describe methods of follow-up } \\
\text { Case-control study—give the eligibility criteria, and the sources and methods of case ascer- } \\
\text { tainment and control selection. Give the rationale for the choice of cases and controls } \\
\text { Cross-sectional study - give the eligibility criteria, and the sources and methods of selection of } \\
\text { participants }\end{array}$ & 6,7 \\
\hline & & $\begin{array}{l}\text { (b) Cohort study—-for matched studies, give matching criteria and number of exposed and } \\
\text { unexposed } \\
\text { Case-control study—-for matched studies, give matching criteria and the number of controls } \\
\text { per case }\end{array}$ & $\%$ \\
\hline Variables & 7 & $\begin{array}{l}\text { Clearly define all outcomes, exposures, predictors, potential confounders, and effect modifiers. } \\
\text { Give diagnostic criteria, if applicable }\end{array}$ & 7 \\
\hline Data sources/ measurement & $8 *$ & $\begin{array}{l}\text { For each variable of interest, give sources of data and details of methods of assessment (meas- } \\
\text { urement). Describe comparability of assessment methods if there is more than one group }\end{array}$ & 7 \\
\hline Bias & 9 & Describe any efforts to address potential sources of bias & $\%$ \\
\hline Study size & 10 & Explain how the study size was arrived at & $6,7,8$ \\
\hline Quantitative variables & 11 & $\begin{array}{l}\text { Explain how quantitative variables were handled in the analyses. If applicable, describe which } \\
\text { groupings were chosen and why }\end{array}$ & 7,8 \\
\hline \multirow[t]{5}{*}{ Statistical methods } & \multirow[t]{5}{*}{12} & (a) Describe all statistical methods, including those used to control for confounding & 7,8 \\
\hline & & (b) Describe any methods used to examine subgroups and interactions & 6,7 \\
\hline & & (c) Explain how missing data were addressed & $\%$ \\
\hline & & $\begin{array}{l}\text { (d) Cohort study_if applicable, explain how loss to follow-up was addressed } \\
\text { Case-control study-if applicable, explain how matching of cases and controls was addressed } \\
\text { Cross-sectional study-if applicable, describe analytical methods taking account of sampling } \\
\text { strategy }\end{array}$ & 6,7 \\
\hline & & (e) Describe any sensitivity analyses & $\%$ \\
\hline
\end{tabular}


Table 5 Results

\begin{tabular}{|c|c|c|c|}
\hline \multirow[t]{3}{*}{ Participants } & $13^{*}$ & $\begin{array}{l}\text { (a) Report numbers of individuals at each stage of study-e.g., numbers potentially eligible, examined } \\
\text { for eligibility, confirmed eligible, included in the study, completing follow-up, and analyzed }\end{array}$ & 8 \\
\hline & & (b) Give reasons for non-participation at each stage & 8 \\
\hline & & (c) Consider use of a flow diagram & Fig. 1 \\
\hline \multirow[t]{3}{*}{ Descriptive data } & $14^{*}$ & $\begin{array}{l}\text { (a) Give characteristics of study participants (e.g., demographic, clinical, social) and information on } \\
\text { exposures and potential confounders }\end{array}$ & $8-16$ \\
\hline & & (b) Indicate number of participants with missing data for each variable of interest & $8-12$ \\
\hline & & (c) Cohort study—summarize follow-up time (e.g., average and total amount) & $6,8,9$ \\
\hline \multirow[t]{3}{*}{ Outcome data } & $15^{*}$ & Cohort study—report numbers of outcome events or summary measures over time & Figs. $3,4,5$ \\
\hline & & Case-control study-report numbers in each exposure category, or summary measures of exposure & $\%$ \\
\hline & & Cross-sectional study—report numbers of outcome events or summary measures & $13,14,15,16$ \\
\hline \multirow[t]{3}{*}{ Main results } & 16 & $\begin{array}{l}\text { (a) Give unadjusted estimates and, if applicable, confounder-adjusted estimates and their precision } \\
\text { (e.g., } 95 \% \text { confidence interval). Make clear which confounders were adjusted for and why they were } \\
\text { included }\end{array}$ & $8,13,14,15,16$ \\
\hline & & (b) Report category boundaries when continuous variables were categorized & $\%$ \\
\hline & & $\begin{array}{l}\text { (c) If relevant, consider translating estimates of relative risk into absolute risk for a meaningful time } \\
\text { period }\end{array}$ & $\%$ \\
\hline Other analyses & 17 & Report other analyses done-e.g., analyses of subgroups and interactions, and sensitivity analyses & Figs. $3,4,5$ \\
\hline \multicolumn{4}{|l|}{ Discussion } \\
\hline Key results & 18 & Summarize key results with reference to study objectives & $17,18,19$ \\
\hline Limitations & 19 & $\begin{array}{l}\text { Discuss limitations of the study, taking into account sources of potential bias or imprecision. Discuss } \\
\text { both direction and magnitude of any potential bias }\end{array}$ & 20 \\
\hline Interpretation & 20 & $\begin{array}{l}\text { Give a cautious overall interpretation of results considering objectives, limitations, multiplicity of } \\
\text { analyses, results from similar studies, and other relevant evidence }\end{array}$ & $17,18,19$ \\
\hline Generalisability & 21 & Discuss the generalisability (external validity) of the study results & $17,18,19$ \\
\hline \multicolumn{4}{|c|}{ Other information } \\
\hline Funding & 22 & $\begin{array}{l}\text { Give the source of funding and the role of the funders for the present study and, if applicable, for the } \\
\text { original study on which the present article is based }\end{array}$ & 1,19 \\
\hline
\end{tabular}

Acknowledgements We greatly acknowledge the excellent work of Iris Bolle (Department of Pediatric Cardiology and Intensive Care Medicine, University Medical Center, Goettingen) in contacting the patients and organizing follow-up appointments.

Funding Open Access funding enabled and organized by Projekt DEAL. This manuscript is based on two research projects. The first one was funded by the German Research Foundation (Deutsche Forschungsgemeinschaft- DFG) under grant numbers WE 2670/1-1 and GE1167/2-1 (URL: https://www.dfg.de). The follow-up was funded by Stiftung Kinderherzen, grant number W-GÖ-014/2016 (URL: https:// www.kinderherzen.de). There are no further conflicts of interest for any author of these manuscript.

\section{Declarations}

Conflict of interest There is no conflict of interest.

Ethics approval The first part of the study was reviewed and approved by the ethics committee of Hannover Medical School under no. 3710 (date: 04-10-2004) and by the University Clinic of Goettingen under no. 10/2/01 (date: 01-03-2001), and the second part was reviewed and approved by the ethics committee of the University of Goettingen under nr. $15 / 8 / 14$.
Open Access This article is licensed under a Creative Commons Attribution 4.0 International License, which permits use, sharing, adaptation, distribution and reproduction in any medium or format, as long as you give appropriate credit to the original author(s) and the source, provide a link to the Creative Commons licence, and indicate if changes were made. The images or other third party material in this article are included in the article's Creative Commons licence, unless indicated otherwise in a credit line to the material. If material is not included in the article's Creative Commons licence and your intended use is not permitted by statutory regulation or exceeds the permitted use, you will need to obtain permission directly from the copyright holder. To view a copy of this licence, visit http://creativecommons.org/licenses/by/4.0/.

\section{References}

1. Baumgartner H, De Backer J, Babu-Narayan SV, Budts W, Chessa M, Diller GP, Lung B, Kluin J, Lang IM, Meijboom F, Moons P, Mulder BJM, Oechslin E, Roos-Hesselink JW, Schwerzmann M, Sondergaard L, Zeppenfeld K, Group ESCSD (2020) 2020 ESC Guidelines for the management of adult congenital heart disease. Eur Heart J. https://doi.org/10.1093/eurhe artj/ehaa554

2. Buber J, Valente AM (2018) Predicting survival in adults with congenital heart disease: what are the odds? Heart 104(20):16431644. https://doi.org/10.1136/heartjnl-2018-312975 
3. Seidel L, Nebel K, Achenbach S, Bauer U, Ewert P, Freilinger S, Gundlach U, Kaemmerer H, Nagdyman N, Oberhoffer R, Pieper L, Reinhard W, Sanftenberg L, Schelling J, Weyand M, Neidenbach R (2020) Facts about the general medical care of adults with congenital heart defects: experience of a tertiary care center. J Clin Med. https://doi.org/10.3390/jcm9061943

4. Norozi K, Wessel A, Alpers V, Arnhold JO, Geyer S, Zoege M, Buchhorn R (2006) Incidence and risk distribution of heart failure in adolescents and adults with congenital heart disease after cardiac surgery. Am J Cardiol 97(8):1238-1243. https://doi.org/ 10.1016/j.amjcard.2005.10.065

5. Norozi K, Zoege M, Buchhorn R, Wessel A, Geyer S (2006) The influence of congenital heart disease on psychological conditions in adolescents and adults after corrective surgery. Congenit Heart Dis 1(6):282-288. https://doi.org/10.1111/j.1747-0803.2006. 00048.x

6. Geyer S, Fleig K, Norozi K, Robbel L, Paul T, Muller M, Dellas C (2021) Life chances after surgery of congenital heart disease: A case-control-study of inter- and intragenerational social mobility over 15 years. PLoS ONE 16(2):e0246169. https://doi. org/10.1371/journal.pone.0246169

7. Neidenbach R, Niwa K, Oto O, Oechslin E, Aboulhosn J, Celermajer D, Schelling J, Pieper L, Sanftenberg L, Oberhoffer R, de Haan F, Weyand M, Achenbach S, Schlensak C, Lossnitzer D, Nagdyman N, von Kodolitsch Y, Kallfelz HC, Pittrow D, Bauer UMM, Ewert P, Meinertz T, Kaemmerer H (2018) Improving medical care and prevention in adults with congenital heart disease-reflections on a global problem-part I: development of congenital cardiology, epidemiology, clinical aspects, heart failure, cardiac arrhythmia. Cardiovasc Diagn Ther 8 (6):705-715. https://doi.org/10.21037/cdt.2018.10.15

8. Khairy P, Ionescu-Ittu R, Mackie AS, Abrahamowicz M, Pilote L, Marelli AJ (2010) Changing mortality in congenital heart disease. J Am Coll Cardiol 56(14):1149-1157. https://doi.org/ 10.1016/j.jacc.2010.03.085

9. Diller GP, Kempny A, Alonso-Gonzalez R, Swan L, Uebing A, Li W, Babu-Narayan S, Wort SJ, Dimopoulos K, Gatzoulis MA (2015) Survival prospects and circumstances of death in contemporary adult congenital heart disease patients under followup at a large tertiary centre. Circulation 132(22):2118-2125. https://doi.org/10.1161/CIRCULATIONAHA.115.017202

10. Nyboe C, Karunanithi Z, Nielsen-Kudsk JE, Hjortdal VE (2018) Long-term mortality in patients with atrial septal defect: a nationwide cohort-study. Eur Heart J 39(12):993-998. https:// doi.org/10.1093/eurheartj/ehx687

11. Menting ME, Cuypers JA, Opic P, Utens EM, Witsenburg M, van den Bosch AE, van Domburg RT, Meijboom FJ, Boersma E, Bogers AJ, Roos-Hesselink JW (2015) The unnatural history of the ventricular septal defect: outcome up to 40 years after surgical closure. J Am Coll Cardiol 65(18):1941-1951. https://doi.org/10. 1016/j.jacc.2015.02.055

12. Yu C, Moore BM, Kotchetkova I, Cordina RL, Celermajer DS (2018) Causes of death in a contemporary adult congenital heart disease cohort. Heart 104(20):1678-1682. https://doi.org/10. 1136/heartjnl-2017-312777

13. Geyer S, Zoege M, Norozi K, Kempa A, Buchhorn R, Wessel A (2008) Study participation and nonresponse in a population of adolescents and adults with operated congenital heart disease (GUCH patients). Congenit Heart Dis 3(1):26-32. https://doi.org/ 10.1111/j.1747-0803.2007.00159.x

14. Rychik J, Atz AM, Celermajer DS, Deal BJ, Gatzoulis MA, Gewillig MH, Hsia TY, Hsu DT, Kovacs AH, McCrindle BW, Newburger JW, Pike NA, Rodefeld M, Rosenthal DN, Schumacher KR, Marino BS, Stout K, Veldtman G, Younoszai AK, d'Udekem Y, American Heart Association Council on Cardiovascular Disease in the Y, Council on C, Stroke N (2019) Evaluation and management of the child and adult with fontan circulation: a scientific statement from the american heart association. Circulation. https://doi.org/10.1161/CIR.0000000000000696

15. Diller GP (2014) Chasing a moving target: outcome and risk stratification in patients with transposition of the great arteries after atrial switch operation. Eur Heart J 35(25):1637-1641. https:// doi.org/10.1093/eurheartj/ehu132

16. Cuypers JA, Eindhoven JA, Slager MA, Opic P, Utens EM, Helbing WA, Witsenburg M, van den Bosch AE, Ouhlous M, van Domburg RT, Rizopoulos D, Meijboom FJ, Bogers AJ, RoosHesselink JW (2014) The natural and unnatural history of the Mustard procedure: long-term outcome up to 40 years. Eur Heart J 35(25):1666-1674. https://doi.org/10.1093/eurheartj/ehu102

17. Cuypers JA, Menting ME, Konings EE, Opic P, Utens EM, Helbing WA, Witsenburg M, van den Bosch AE, Ouhlous M, van Domburg RT, Rizopoulos D, Meijboom FJ, Boersma E, Bogers AJ, Roos-Hesselink JW (2014) Unnatural history of tetralogy of Fallot: prospective follow-up of 40 years after surgical correction. Circulation 130(22):1944-1953. https://doi.org/10.1161/CIRCU LATIONAHA.114.009454

18. Agarwal S, Sud K, Menon V (2016) Nationwide hospitalization trends in adult congenital heart disease across 2003-2012. J Am Heart Assoc. https://doi.org/10.1161/JAHA.115.002330

19. Mach F, Baigent C, Catapano AL, Koskinas KC, Casula M, Badimon L, Chapman MJ, De Backer GG, Delgado V, Ference BA, Graham IM, Halliday A, Landmesser U, Mihaylova B, Pedersen TR, Riccardi G, Richter DJ, Sabatine MS, Taskinen MR, Tokgozoglu L, Wiklund O, Group ESCSD (2020) 2019 ESC/EAS Guidelines for the management of dyslipidaemias: lipid modification to reduce cardiovascular risk. Eur Heart J 41(1):111-188. https://doi.org/10.1093/eurheartj/ehz455

20. Helm PC, Kaemmerer H, Breithardt G, Sticker EJ, Keuchen R, Neidenbach R, Diller GP, Tutarel O, Bauer UMM (2017) Transition in patients with congenital heart disease in germany: results of a nationwide patient survey. Front Pediatr 5:115. https://doi. org/10.3389/fped.2017.00115

21. Mackie AS, Ionescu-Ittu R, Therrien J, Pilote L, Abrahamowicz M, Marelli AJ (2009) Children and adults with congenital heart disease lost to follow-up: who and when? Circulation 120(4):302309. https://doi.org/10.1161/CIRCULATIONAHA.108.839464 